\title{
Acúmulo de biomassa em variedades de cana-de-açúcar inoculadas com diferentes estirpes de bactérias diazotróficas ${ }^{1}$
}

\author{
Biomass accumulation in sugarcane varieties inoculated with different strains of \\ diazotrophs
}

\author{
Willian Pereira ${ }^{2}$, José Marcos Leite ${ }^{3}$, Guilherme de Souza Hipólito ${ }^{4}$ Carlos Leandro Rodrigues dos Santos ${ }^{5}$ e \\ Veronica Massena Reis ${ }^{6 *}$
}

\begin{abstract}
RESUMO - O objetivo do estudo foi avaliar a contribuição da inoculação com bactérias diazotróficas, aplicadas individualmente e em mistura, em variedades comerciais de cana-de-açúcar. O experimento foi conduzido no Campo Experimental da Embrapa Agrobiologia, em Seropédica-RJ, Brasil. O delineamento experimental foi em blocos casualizados, com parcelas subdivididas e com seis repetições. Foram utilizadas seis variedades de cana-de-açúcar e seis tratamentos: controle absoluto, controle nitrogenado, inoculação individual das estipes: BR 11512, BR 11724 e BR 11411; além de inoculação com um coquetel composto por cinco estirpes de bactérias diazotróficas. Foi observada diferença entre variedades, entre tratamentos e uma interação entre tratamentos e variedades. Para todos os parâmetros avaliados não foi observado resposta nas variedades de cana-de-açúcar RB855536 e RB92606. Na variedade RB918639, houve apenas diferença no acúmulo de biomassa verde. Não foi observada nenhuma diferença entre tratamentos no acúmulo de nitrogênio total do ponteiro. A variedade mais responsiva à inoculação foi a RB867515, diferenciando no acúmulo de biomassa seca e fresca. Este estudo mostrou que a inoculação promove o acúmulo de biomassa, sendo a contribuição diferente entre variedades e estirpes de bactérias, sugerindo uma interação entre os fatores estudados. A variedade RB867515 é promissora para os estudos de inoculação com bactérias diazotróficas.
\end{abstract}

Palavras-chave: Cana-de-açúcar. Crescimento (plantas). Plantas-inoculação.

\begin{abstract}
The objective of this study was to evaluate the contribution of inoculation with diazotrophs, applied both individually and in combination, in commercial varieties of sugarcane. The experiment was carried out at the experimental grounds of Embrapa Agrobiologia, in Seropédica, Rio de Janeiro, Brazil. The experimental design was of randomised blocks, with sub-divided plots and six replications. Six varieties of sugarcane with six treatments were used: control, control with nitrogen, inoculation of the individual strains: BR 11512, BR 11724 and BR 11411, in addition to inoculation with a cocktail consisting of five strains of diazotrophs. Differences were observed between varieties and between treatments, and an interaction observed between the treatments and varieties. For all the parameters evaluated, no response was observed in the sugarcane varieties RB855536 and RB92606. In the variety RB918639, the only difference was in the accumulation of green biomass. No difference was observed between the treatments for total nitrogen accumulation. The most responsive variety to inoculation was RB867515, differing in the accumulation of fresh and dry biomass. This study showed that inoculation promotes the accumulation of biomass, the contribution being different for the varieties and strains of bacteria, suggesting an interaction between the factors studied. The variety RB867515 is promising for use in studies of inoculation with diazotrophs.
\end{abstract}

Key words: Sugarcane. Plant growth. Plant-inoculation.

\footnotetext{
*Autor para correspondência

${ }^{1}$ Recebido para publicação em 16/11/2010; aprovado em 28/10/2012

Pesquisa financiada pelo CNPq projeto MCT/CT Agro 558329/2009-8 e Fundação Carlos Chagas de Amparo e Pesquisa do Estado do Rio de Janeiro/ Faperj pela Bolsa Cientista do Nosso Estado do ultimo autor

${ }^{2}$ Programa de Pós-Graduação em Agronomia/Ciência do Solo, UFRRJ, BR 465, Km 7, Seropédica-RJ, Brasil, 23.890-000, willpmg@ yahoo.com.br ${ }^{3}$ Programa de Pós-Graduação em Solos e Nutrição de Plantas/Universidade de São Paulo, Escola Superior de Agricultura Luiz de Queiroz, Caixa Postal 96, Piracicaba-SP, Brasil, 13.400-970,jmleite@cena.usp.br

${ }^{4}$ BASF/Regente Feijó, Piracicaba-SP, Brasil, hipolito.guilherme@gmail.com

${ }^{5}$ Programa de Pós-Graduação em Agronomia/Ciência do Solo, Departamento de Tecnologia/UNESP, "Júlio de Mesquita Filho"/FCAV, Campus

Jaboticabal, Prof. Paulo Donato Castellane, Jaboticabal-SP, Brasil 14.884-900, caleufrrj@ bol.com.br

${ }^{6}$ Embrapa Agrobiologia, BR 465, Km 7, Seropédica-RJ, Brasil, 23.890-000 veronica@ cnpab.embrapa.br
} 


\section{INTRODUÇÃO}

A cana-de-açúcar (Saccharum officinarum L.) ocupa no Brasil uma área de 8 milhões de hectares, com um aumento de $8,4 \%$ da área plantada comparada com a safra de 2009 (COMPANHIA NACIONAL DE ABASTECIMENTO, 2011). É uma importante cultura para a economia do país pelo complexo industrial que gira em torno do seu cultivo. Essa atividade representa $2 \%$ do PIB nacional e fatura anualmente mais de US\$ 28,2 bilhões, gerando aproximadamente um milhão de empregos diretos (de SOUSA; MACEDO, 2010). Na matriz energética brasileira, 45,5\% é renovável e 17,4\% é derivada da cana-de-açúcar (BRASIL, 2011). Na agricultura nacional, dos 340 milhões de hectares disponíveis para os cultivos, apenas $0,9 \%$ é ocupada por cana-de-açúcar, com isso, existe um imenso potencial de expansão da área plantada (SOCCOL et al., 2010).

Com o aumento da área cultivada, cresce também a demanda por novas tecnologias de produção. Nesse sentido, é fundamental que se busquem alternativas que reduzam os impactos e promovam ganhos de produtividade, sem comprometer o balanço energético da cultura. Na busca por estas alternativas, tem se intensificado os estudos com a aplicação de microrganismos com capacidade de promoção do crescimento vegetal (OLIVEIRA et al., 2006; REIS et al., 2009).

A cana-de-açúcar é capaz de se associar com uma grande diversidade de bactérias e obter diversos benefícios (BALDANI et al., 2002). A descoberta de bactérias endofíticas colonizando plantas dessa cultura em populações elevadas, como Gluconacetobacter diazotrophicus (REIS; OLIVARES; DOBEREINER, 1994), Herbaspirillum seropedicae e H. rubrisubalbicans (OLIVARES et al., 1996), Azospirillum spp. e Burkholderia spp. (REIS et al., 2004), possibilitou o entendimento de algumas relações estabelecidas entre a planta e as bactérias.

Essas bactérias mencionadas são benéficas às plantas e possuem a capacidade de colonizar as raízes e outros tecidos internos do vegetal, sem causar sintomas de doenças (REIS et al., 2006). É uma relação simbiótica, onde as bactérias se beneficiam por colonizarem um ambiente protegido contra vários estresses bióticos e abióticos (REINHOLD-HUREK; HUREK, 1998), em contrapartida podem promover o crescimento da planta hospedeira através de diversos mecanismos (GOVINDARAJAN et al., 2006; MUTHUKUMARASAMY et al., 2006; SEVILLA et $a l .$, 1998). Além da fixação biológica de nitrogênio $(\mathrm{FBN})$, promovem o crescimento da planta de várias formas. Efeitos diretos como a produção de fitormônios (DOBBELAERE; VANDERLEYDEN; OKON, 2003), síntese de sideróforos (NEILANDS; LEONG, 1986), solubilização de fósforo (RODRIGUEZ; FRAGA, 1999) e aceleração dos processos de mineralização de nutrientes(PERSELLO-CARTINEAUX;NUSSAUME; ROBAGLIA, 2003) e indiretos como o antagonismo a fitopatógenos (MUTHUKUMARASAMY; REVATHI; VADIVELU, 2000), entre outros efeitos benéficos. Porém, a FBN é o mecanismo mais estudado (BALDANI et al., 2002; BODDEY et al., 2003). Estudos de quantificação da FBN pela população natural de bactérias e pelo efeito da inoculação de misturas bacterianas verificaram resposta positiva sobre a FBN, com contribuições médias entre 30 e $60 \%$ do nitrogênio acumulado na planta (OLIVEIRA et al., 2006; URQUIAGA; CRUZ; BODDEY, 1992).

A inoculação de bactérias diazotróficas responde diferentemente ao genótipo da planta, e ao tipo de solo e ambiente (OLIVEIRA et al., 2006). Deve-se responder a estes questionamentos, para que a tecnologia de inoculação com microrganismos contribua de forma efetiva para ganhos de produtividade nos canaviais brasileiros, com redução das adubações nitrogenadas, o que contribui para a sustentabilidade dos agroecossistemas.

Assim, o objetivo desse trabalho foi avaliar a contribuição da inoculação com bactérias diazotróficas, individuais e em mistura, no acúmulo de massa fresca e seca de parte aérea e no acúmulo de nitrogênio de seis variedades comerciais de cana-de-açúcar.

\section{MATERIAL E MÉTODOS}

O experimento foi instalado no campo experimental da Embrapa Agrobiologia, localizada no município de Seropédica-RJ, em um Planossolo Háplico distrófico. A área experimental situa-se a $22^{\circ} 45^{\prime} \mathrm{S}, 43^{\circ} 40^{\prime} \mathrm{W}$ e $26 \mathrm{~m}$ de altitude e o tipo de clima da região, segundo a classificação de Köppen é Aw, com verão úmido e inverno seco, apresentando temperatura média de $24,6{ }^{\circ} \mathrm{C}$ e precipitação média de $1.200 \mathrm{~mm}$ por ano, sendo julho e agosto os meses mais secos.

A análise de solo para fins de fertilidade foi realizada em amostras provenientes da camada de 0 a 20 $\mathrm{cm}$, apresentando os seguintes resultados: $6,1 \mathrm{de} \mathrm{pH}$ em

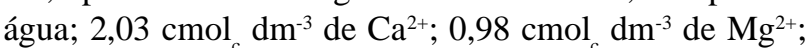
$0,0 \mathrm{cmol}_{\mathrm{c}} \mathrm{dm}^{-3} \mathrm{de} \mathrm{Al}^{3+} ; 9,0 \mathrm{mg} \mathrm{dm}^{-3} \mathrm{de} \mathrm{P} ; 24,25 \mathrm{mg} \mathrm{dm}^{-3} \mathrm{de}$ $\mathrm{K}$ e $0,58 \mathrm{~g} \mathrm{~kg}^{-1}$ de N. O preparo do solo consistiu de uma aração, seguida de gradagem e sulcação. Foram aplicados no fundo do sulco de plantio, $100 \mathrm{~kg} \mathrm{ha}^{-1} \mathrm{de}_{2} \mathrm{O}_{5}$, na forma de Superfosfato Simples e $80 \mathrm{~kg} \mathrm{ha}^{-1}$ de $\mathrm{K}_{2} \mathrm{O}$, na forma de Cloreto de Potássio, distribuídos manualmente. As parcelas adubadas com nitrogênio receberam o equivalente 
a $100 \mathrm{~kg} \mathrm{ha}^{-1}$ de $\mathrm{N}$ aplicados na forma de Uréia em cobertura, incorporado ao solo 30 dias após o plantio.

Foram utilizadas seis cultivares comerciais de cana-de-açúcar: RB72454, RB867515, RB92579, RB918639, RB92606 e RB855536, provenientes do campo experimental da Universidade Federal Rural do Rio de Janeiro, localizado em Campos dos Goytacazes - RJ. Os colmos selecionados foram cortados, e os toletes contendo três gemas foram plantados na densidade de 15 gemas por metro linear. Todos os toletes sofreram um tratamento térmico curto, sendo imersos em água a $52^{\circ} \mathrm{C}$ por 30 minutos.

O delineamento experimental utilizado foi em bloco casualizado, em esquema de parcelas subdivididas, com seis repetições. As parcelas consistiram em quatro linhas com $12 \mathrm{~m}$ de comprimento, com espaçamento de $0,60 \mathrm{~m}$. As subparcelas consistiram de quatro linhas de 2,0 $\mathrm{m}$ de comprimento com $0,60 \mathrm{~m}$ de espaçamento, sendo consideradas como área útil na colheita as duas linhas centrais. Nas parcelas foram avaliadas as variedades de cana-de-açúcar e nas subparcelas os seis tratamentos: uma testemunha sem inoculação e sem aplicação de nitrogênio, uma testemunha sem inoculação e com aplicação de $100 \mathrm{~kg} \mathrm{ha}^{-1}$ de $\mathrm{N}$ (na forma de Uréia), inoculação com um coquetel de bactérias diazotróficas (OLIVEIRA et al., 2006) utilizando as estirpes: BR11335 (Herbaspirillum seropedicae), BR11504 (Herbaspirillum rubrisubalbicans), BR11281 ${ }^{\mathrm{T}} \quad$ (Gluconacetobacter diazotrophicus), BR11366 ${ }^{\mathrm{T}}$ (Burkholderia tropica) e BR11145 (Azospirillum amazonense) e inoculação de três estirpes individuais de bactérias diazotróficas pré-selecionadas em estudos preliminares na Embrapa Agrobiologia: BR 11512 (Herbaspirillum rubrisubalbicans), BR 11411 (Herbaspirillum seropedicae) e BR 11724 (Burkhoderia gladioli). Todas as estirpes utilizadas foram cedidas pelo Laboratório de Coleção de Culturas da Embrapa Agrobiologia.

Os inoculantes foram preparados a partir de colônias isoladas, e cultivadas em tubos de ensaio, sob agitação a $175 \mathrm{rpm}$, a $30{ }^{\circ} \mathrm{C}$ por 24 horas. Os meios líquidos utilizados para o crescimento foram: LGI-P com acréscimo de $10 \mathrm{mmol}_{\mathrm{c}} \mathrm{L}^{-1}$ de $\mathrm{NH}_{4} \mathrm{SO}_{4}$ com $\mathrm{pH} 5,5$ para a estirpe BR11281 $1^{\mathrm{T}}$; JNFb com $1 \mathrm{~g} \mathrm{NH}_{4} \mathrm{Cl}$, pH 5,8 para as estirpes BR11335, BR11504 e BR11512; LGI com $1 \mathrm{~g}$ de $\mathrm{KNO}_{3}$, pH 6,0 a 6,2 para a estirpe BR11145 e JMV com $10 \mathrm{mmol} \mathrm{L}^{-1}$ de glutamato de sódio, $\mathrm{pH} \mathrm{5,0} \mathrm{para} \mathrm{as}$ estirpes BR $11366^{\mathrm{T}}$ e BR11724.

Foi utilizado $1 \mathrm{~mL}$ das suspensões celulares para a inoculação em $200 \mathrm{~mL}$ de meio líquido $\mathrm{NFb}$ modificado (BURDMAN et al., 1998), com: $5 \mathrm{~g} \mathrm{~L}^{-1}$ de sacarose e $\mathrm{pH}$ 6,0 a 6,2 para a estirpe BR $11145 ; 100 \mathrm{~g} \mathrm{~L}^{-1}$ de sacarose e pH 5,5 para a estirpe BR11281; $5 \mathrm{~g} \mathrm{~L}^{-1}$ de manitol, $\mathrm{pH}$ 5,0 a 5,4 para as estirpes BR11366 e BR11724; $5 \mathrm{~g} \mathrm{~L}^{-1}$ de ácido málico, pH 5,8 para as estirpes BR11335, BR11504,
BR11512 e BR 11411. Foi adicionado ainda, $1 \mathrm{~mL}$ de frutose a $0,7 \%$ (1:10) em tampão fosfato $0,5 \mathrm{~mol} \mathrm{~L}^{-1}$ esterilizado em filtro Millipore $0,2 \mu \mathrm{m}$. A contagem das células bacterianas foi feita em câmara de Neubauer. A densidade de células utilizadas foi ao redor de $10^{9}$ células $\mathrm{mL}^{-1}$.

Os inoculantes líquidos foram diluídos 1:100 $(\mathrm{p} / \mathrm{v})$ em água, resultando em uma solução bacteriana com concentração aproximada de $10^{7}$ células $\mathrm{mL}^{-1}$ para as estirpes individuais, e uma concentração de $10^{8}$ células $\mathrm{mL}^{-1}$ para o inoculante em coquetel. Como recipiente para inoculação, utilizou-se uma caixa d'água com capacidade para $500 \mathrm{~L}$, onde os toletes ficaram imersos no inoculante bacteriano por $30 \mathrm{~min}$, sendo plantados em seguida.

As plantas foram colhidas 210 dias após o plantio. Durante o corte, realizado manualmente, a parte aérea foi separada em colmo, folhas secas e ponteiro (folhas verdes). As variáveis analisadas foram: massa fresca e seca de colmo, folhas secas e ponteiro, peso médio de cada colmo e o acúmulo de nitrogênio no ponteiro. A pesagem do material fresco foi realizada, imediatamente, após o corte. O número de perfilhos foi obtido pela contagem dos colmos nas duas linhas centrais da parcela. Para determinação da massa seca foi realizada uma sub-amostragem de colmo, folha seca e ponteiro em cada parcela, sendo pesadas imediatamente. Em seguida, foram levadas para estufa de ventilação forçada com temperatura de $65{ }^{\circ} \mathrm{C}$, sendo pesadas após a estabilização das massas. Após a secagem e pesagem, o material foi moído e levado para análise do nitrogênio contido nos tecidos, sendo analisado pelo método semi-micro Kjeldahl (ALVES et al., 1994).

Os testes estatísticos foram realizados com auxílio dos pacotes estatísticos SAEG 9.1 e SISVAR. Inicialmente, foram analisadas a normalidade e homogeneidade das variâncias dos erros por meio dos testes de Lilliefors e de Cochran \& Bartley, respectivamente. Para verificar o efeito dos tratamentos e das variedades, os resultados foram submetidos à análise de variância (ANOVA) utilizando o teste $\mathrm{F}$, ao nível de $90 \%$ de confiança, observando a interação entre tratamentos e variedades. Posteriormente, para as causas de variação significativas foi aplicado o teste de Scott Knott, a 10\% de probabilidade.

\section{RESULTADOS E DISCUSSÃO}

Para todos os parâmetros estudados observou-se diferença significativa entre variedades, o que pode ser atribuído às características específicas de cada genótipo, além de rusticidade, diferença de resposta à adubação e precocidade. Considerando as respostas dos tratamentos para cada variedade, e a interação entre variedades e tratamentos, 
constatou-se diferença estatística para a maioria dos parâmetros estudados. Para todos os parâmetros avaliados, não foi observada resposta nas variedades RB855536 e RB92606. Na variedade RB918639, houve resposta apenas no acúmulo de biomassa verde do ponteiro, mas não influenciou a produção de biomassa da parte aérea total.

Quanto ao acúmulo de massa fresca de colmos destaca-se a variedade RB867515, que apresentou maior resposta em todos os parâmetros avaliados, nos tratamentos nitrogenados, tratamento com aplicação do inoculante misto e inoculação com a estirpe BR 11724. E na variedade RB72454, no tratamento com inoculação da estirpe BR 11411 diferindo estatisticamente do controle absoluto e dos outros tratamentos (Tabela 1). Silva et al. (2009) observaram respostas positivas na variedade RB72454 em condições de campo, quando aplicado o mesmo inóculo misto utilizado neste ensaio, obtendo ganhos de produtividade de $30 \mathrm{Mg} \mathrm{ha}^{-1}$ quando comparado com o controle não inoculado.

Reis et al. (2009) desenvolveram estudos de inoculação com o coquetel de bactérias diazotróficas em três localidades no Estado do Rio de Janeiro, sendo observado em um dos ensaios aumento significativo de produtividade na variedade RB867515. O aumento de produtividade nesta variedade é de grande interesse dos produtores, pois a RB867515 é, atualmente, a principal variedade de cana-de-açúcar cultivada na região Centro-Sul, respondendo por $20,5 \%$ da área plantada (CHAPOLA et al., 2010).

A variedade RB72454, progenitora da RB867515, também apresentou resposta positiva quanto à produção de massa fresca de colmos, quando inoculada com bactérias diazotróficas, porém, a maior resposta observada foi com a inoculação da estirpe BR 11411, o oposto da RB867515, com acúmulo significativo de biomassa fresca em relação aos demais tratamentos, apresentando $69 \%$ de incremento quando comparado com o controle absoluto. As demais variedades estudadas não apresentaram resposta à inoculação e a adubação nitrogenada neste parâmetro. A especificidade entre variedade e bactéria foi citada por Reis et al. (2006) que ressaltaram que a eficiência da inoculação depende do genótipo da planta.

Houve aumento significativo no teor de nitrogênio do ponteiro na variedade RB72454 em relação ao controle absoluto nos tratamentos com adubação nitrogenada, inoculação mista e inoculação com a estirpe BR 11411 (Tabela 2). URQUIAGA; CRUZ; BODDEY (1992) estudaram a contribuição da FBN em diversas variedades de cana-de-açúcar e neste estudo foi observada a contribuição na nutrição nitrogenada desta variedade. Uma das possíveis explicações para esta resposta a FBN é o fato desse genótipo ter sido melhorado geneticamente para adaptação em solos de baixa fertilidade, que pode ter selecionado essa cultivar para uma melhor associação com organismos fixadores de nitrogênio (BALDANI et al., 2002).

A variedade RB72454 já foi a mais plantada nos canaviais brasileiros, porém, nos últimos anos observa-se um declínio da área plantada (CHAPOLA et al., 2010). Ressalta-se, porém, a importância desta variedade em cruzamentos visando a obtenção de genótipos com capacidade de associação com bactérias capazes de fixar o $\mathrm{N}$ do ar, conforme estudos com balanço de $\mathrm{N}$ e técnicas isotópicas com ${ }^{15} \mathrm{~N}$, que comprovaram a contribuição da FBN (URQUIAGA; CRUZ; BODDEY, 1992). Além disso, a maioria desses organismos apresenta outras formas de promoção de crescimento, como a produção de fitormônios, resistência a estresse, produção de sideróforos e antibiose, além do estímulo de sistemas de transporte de íons (DOBBELAERE; VANDERLEYDEN; OKON, 2003; MUTHUKUMARASAMY et al., 2006; NEILANDS; LEONG, 1986; RODRIGUEZ; FRAGA, 1999). Govindarajan et al. (2006), observaram que a inoculação promoveu um incremento do sistema radicular em relação à parte aérea, explorando maior volume de solo, maximizando a absorção de água e nutrientes, inclusive de N.

Quanto ao peso de colmos, foi observada resposta entre variedades e entre tratamentos somente na variedade RB72454, em que a adubação nitrogenada e todos os tratamentos de inoculação proporcionaram resposta significativa em relação à testemunha, não apresentando diferença entre estirpes inoculadas e nitrogênio.

Quanto ao acúmulo de biomassa seca total, houve resposta significativa aos tratamentos. As variedades que mais se destacaram foram a RB867515, quando inoculada com o coquetel e a estirpe BR11724, apresentando um acúmulo de 14,0 e 11,9 $\mathrm{Mg} \mathrm{ha}^{-1}$, respectivamente, diferenciandodocontroleabsolutoedosdemaistratamentos. $\mathrm{Na}$ variedade RB72454, com adubação nitrogenada e inoculada com a estirpe BR11411, houve acúmulo de 8,8 e 9,1 Mg ha ${ }^{-1}$, respectivamente. Na variedade RB92579, adubada com nitrogênio e no tratamento inoculado com a estirpe BR11724, acumulando 11,2 e $12,7 \mathrm{Mg} \mathrm{ha}^{-1}$, respectivamente. Nas outras três variedades: RB855536, RB92606 e RB918639, não foram observadas respostas.

Foi observado um decréscimo na produção de matéria seca de colmos e total nas variedades RB867515 e RB92579 quando inoculada com Herbaspirillum seropedicae estirpes BR11512 e BR11411, e na matéria seca total da variedade RB72454 inoculada com BR11512. Este efeito antagônico também foi observado por Oliveira et al. (2009), que foi atribuído à uma interação específica entre hospedeiro e alguns genótipos de cana-de-açúcar, que é causado pela troca de fotoassimilados e nutrientes entre o hospedeiro e a planta. 
Tabela 1 - Média de produção de biomassa verde total $\left(\mathrm{Mg} \mathrm{ha}^{-1}\right)$, separados em ponteiro, colmo e palha, número de colmos por metro e peso por colmo, em seis variedades de cana-de-açúcar, inoculadas com diferentes estirpes de bactérias diazotróficas

\begin{tabular}{|c|c|c|c|c|c|c|c|}
\hline \multirow{2}{*}{ Variedades } & \multirow{2}{*}{ Tratamentos } & \multicolumn{4}{|c|}{ Acúmulo de biomassa verde $\left(\mathrm{Mg} \mathrm{ha}^{-1}\right)$} & \multirow{2}{*}{$\mathrm{N}^{o}$ de colmos $\mathrm{m}^{-1}$} & \multirow{2}{*}{ Peso colmo $(\mathrm{kg})$} \\
\hline & & Ponteiro & Colmo & Palha & Total & & \\
\hline \multirow{6}{*}{ RB867515 } & Controle & $10,70 \mathrm{a}$ & $22,15 \mathrm{~b}$ & $2,50 \mathrm{a}$ & $35,3 \mathrm{a}$ & $14,50 \mathrm{a}$ & $0,77 \mathrm{a}$ \\
\hline & Nitrogênio & $9,56 \mathrm{a}$ & 26,16 a & $2,50 \mathrm{a}$ & $38,2 \mathrm{a}$ & $16,00 \mathrm{a}$ & $0,82 \mathrm{a}$ \\
\hline & Coquetel & $9,61 \mathrm{a}$ & 24,27 a & $2,52 \mathrm{a}$ & $36,4 \mathrm{a}$ & $15,83 \mathrm{a}$ & $0,77 \mathrm{a}$ \\
\hline & BR11512 & $7,50 \mathrm{~b}$ & $21,22 \mathrm{~b}$ & $2,10 \mathrm{a}$ & $30,8 \mathrm{~b}$ & 15,17 a & $0,70 \mathrm{a}$ \\
\hline & BR 11724 & $9,08 \mathrm{a}$ & $24,25 \mathrm{a}$ & $2,38 \mathrm{a}$ & $35,7 \mathrm{a}$ & 16,08 a & $0,76 \mathrm{a}$ \\
\hline & BR 11411 & $7,85 \mathrm{~b}$ & $20,76 \mathrm{~b}$ & $2,12 \mathrm{a}$ & $30,7 \mathrm{~b}$ & $14,42 \mathrm{a}$ & $0,73 \mathrm{a}$ \\
\hline \multirow{6}{*}{ RB72454 } & Controle & $5,52 \mathrm{a}$ & $12,36 \mathrm{~b}$ & $1,20 \mathrm{a}$ & $19,1 \mathrm{~b}$ & $13,17 \mathrm{a}$ & $0,47 \mathrm{~b}$ \\
\hline & Nitrogênio & $7,15 \mathrm{a}$ & $15,43 \mathrm{~b}$ & $1,07 \mathrm{a}$ & $23,6 \mathrm{~b}$ & 13,67 a & $0,57 \mathrm{a}$ \\
\hline & Coquetel & $6,56 \mathrm{a}$ & $16,70 \mathrm{~b}$ & $1,42 \mathrm{a}$ & $24,7 \mathrm{~b}$ & $13,25 \mathrm{a}$ & $0,64 \mathrm{a}$ \\
\hline & BR11512 & $7,01 \mathrm{a}$ & $15,72 \mathrm{~b}$ & $1,52 \mathrm{a}$ & $24,2 \mathrm{~b}$ & $12,92 \mathrm{a}$ & $0,61 \mathrm{a}$ \\
\hline & BR 11724 & $6,90 \mathrm{a}$ & $16,66 \mathrm{~b}$ & $1,48 \mathrm{a}$ & $25,1 \mathrm{~b}$ & 13,67 a & $0,68 \mathrm{a}$ \\
\hline & BR 11411 & $7,69 \mathrm{a}$ & $20,88 \mathrm{a}$ & $1,83 \mathrm{a}$ & $30,4 \mathrm{a}$ & $16,25 \mathrm{a}$ & $0,64 \mathrm{a}$ \\
\hline \multirow{6}{*}{ RB92579 } & Controle & $9,67 \mathrm{a}$ & $22,42 \mathrm{a}$ & $2,15 \mathrm{a}$ & $34,2 \mathrm{a}$ & $21,33 \mathrm{a}$ & $0,52 \mathrm{a}$ \\
\hline & Nitrogênio & $9,97 \mathrm{a}$ & $26,57 \mathrm{a}$ & $2,50 \mathrm{a}$ & $39,0 \mathrm{a}$ & $22,50 \mathrm{a}$ & $0,59 \mathrm{a}$ \\
\hline & Coquetel & $9,48 \mathrm{a}$ & $23,75 \mathrm{a}$ & $1,98 \mathrm{a}$ & $35,2 \mathrm{a}$ & $21,42 \mathrm{a}$ & $0,56 \mathrm{a}$ \\
\hline & BR11512 & $8,73 \mathrm{a}$ & $22,48 \mathrm{a}$ & $2,25 \mathrm{a}$ & $33,5 \mathrm{a}$ & $23,42 \mathrm{a}$ & $0,49 \mathrm{a}$ \\
\hline & BR 11724 & $9,02 \mathrm{a}$ & $21,59 \mathrm{a}$ & $2,05 \mathrm{a}$ & $32,7 \mathrm{a}$ & $19,00 \mathrm{~b}$ & $0,57 \mathrm{a}$ \\
\hline & BR 11411 & $9,27 \mathrm{a}$ & $21,49 \mathrm{a}$ & $1,88 \mathrm{a}$ & $32,6 \mathrm{a}$ & $19,42 \mathrm{~b}$ & $0,55 \mathrm{a}$ \\
\hline \multirow{6}{*}{ RB918639 } & Controle & $9,53 \mathrm{a}$ & $17,17 \mathrm{a}$ & $1,35 \mathrm{a}$ & $28,1 \mathrm{a}$ & 13,17 a & $0,65 \mathrm{a}$ \\
\hline & Nitrogênio & $8,45 \mathrm{~b}$ & $18,73 \mathrm{a}$ & $1,52 \mathrm{a}$ & $28,7 \mathrm{a}$ & $13,33 \mathrm{a}$ & $0,70 \mathrm{a}$ \\
\hline & Coquetel & $6,92 \mathrm{~b}$ & $17,23 \mathrm{a}$ & $2,08 \mathrm{a}$ & $26,2 \mathrm{a}$ & $12,00 \mathrm{a}$ & $0,71 \mathrm{a}$ \\
\hline & BR11512 & $7,88 \mathrm{~b}$ & 17,67 a & $1,52 \mathrm{a}$ & $27,1 \mathrm{a}$ & $13,33 \mathrm{a}$ & $0,67 \mathrm{a}$ \\
\hline & BR 11724 & $9,97 \mathrm{a}$ & 17,83 a & $1,87 \mathrm{a}$ & $29,7 \mathrm{a}$ & $13,42 \mathrm{a}$ & $0,66 \mathrm{a}$ \\
\hline & BR 11411 & $9,00 \mathrm{a}$ & $18,65 \mathrm{a}$ & $1,70 \mathrm{a}$ & $29,4 \mathrm{a}$ & $14,92 \mathrm{a}$ & $0,63 \mathrm{a}$ \\
\hline \multirow{6}{*}{ RB92606 } & Controle & $7,22 \mathrm{a}$ & $15,35 \mathrm{a}$ & $2,13 \mathrm{a}$ & $24,7 \mathrm{a}$ & $12,25 \mathrm{a}$ & $0,62 \mathrm{a}$ \\
\hline & Nitrogênio & $6,02 \mathrm{a}$ & $15,30 \mathrm{a}$ & $1,80 \mathrm{a}$ & $23,1 \mathrm{a}$ & $12,58 \mathrm{a}$ & $0,61 \mathrm{a}$ \\
\hline & Coquetel & $8,80 \mathrm{a}$ & $16,65 \mathrm{a}$ & $2,22 \mathrm{a}$ & $27,7 \mathrm{a}$ & $13,33 \mathrm{a}$ & $0,63 \mathrm{a}$ \\
\hline & BR11512 & $6,92 \mathrm{a}$ & $14,50 \mathrm{a}$ & $1,90 \mathrm{a}$ & $23,3 \mathrm{a}$ & $10,92 \mathrm{a}$ & $0,67 \mathrm{a}$ \\
\hline & BR 11724 & $7,20 \mathrm{a}$ & $17,68 \mathrm{a}$ & $2,30 \mathrm{a}$ & $27,2 \mathrm{a}$ & $12,42 \mathrm{a}$ & $0,71 \mathrm{a}$ \\
\hline & BR 11411 & $7,88 \mathrm{a}$ & $19,15 \mathrm{a}$ & $2,48 \mathrm{a}$ & $29,5 \mathrm{a}$ & $13,83 \mathrm{a}$ & $0,69 \mathrm{a}$ \\
\hline \multirow{6}{*}{ RB855536 } & Controle & $6,73 \mathrm{a}$ & $14,24 \mathrm{a}$ & $1,81 \mathrm{a}$ & $22,8 \mathrm{a}$ & $15,67 \mathrm{a}$ & $0,46 \mathrm{a}$ \\
\hline & Nitrogênio & $6,56 \mathrm{a}$ & $14,54 \mathrm{a}$ & $1,38 \mathrm{a}$ & $22,5 \mathrm{a}$ & 15,58 a & $0,46 \mathrm{a}$ \\
\hline & Coquetel & 7,27 a & $13,28 \mathrm{a}$ & $1,52 \mathrm{a}$ & $22,1 \mathrm{a}$ & 14,83 a & $0,45 \mathrm{a}$ \\
\hline & BR11512 & $5,92 \mathrm{a}$ & $11,52 \mathrm{a}$ & $1,30 \mathrm{a}$ & $18,7 \mathrm{a}$ & 13,17 a & $0,41 \mathrm{a}$ \\
\hline & BR 11724 & $6,43 \mathrm{a}$ & $13,67 \mathrm{a}$ & $1,27 \mathrm{a}$ & $21,4 \mathrm{a}$ & $14,25 \mathrm{a}$ & $0,48 \mathrm{a}$ \\
\hline & BR 11411 & $5,82 \mathrm{a}$ & $11,42 \mathrm{a}$ & $1,28 \mathrm{a}$ & $18,5 \mathrm{a}$ & $15,67 \mathrm{a}$ & $0,37 \mathrm{a}$ \\
\hline \multirow{2}{*}{ F calculado } & Variedade & $9,07 * * *$ & $17,42 * * *$ & $10,24 * * *$ & $17,07 * * *$ & $30,52 * * *$ & $13,85^{* * *}$ \\
\hline & Tratamento & $1,20^{\mathrm{ns}}$ & $2,11 *$ & $0,42^{\mathrm{ns}}$ & $1,42^{\mathrm{ns}}$ & $0,82^{\mathrm{ns}}$ & $1,67^{\mathrm{ns}}$ \\
\hline Tratamento x Variedade & & $1,56^{*}$ & $1,61^{*}$ & $0,90^{\mathrm{ns}}$ & $1,5^{*}$ & $1,16^{\mathrm{ns}}$ & $0,96^{\mathrm{ns}}$ \\
\hline CV\% Variedades & & 21,4 & 23,6 & 34,9 & 19,6 & 13,4 & 21,3 \\
\hline CV\% Tratamentos & & 21,5 & 20,2 & 33,6 & 18,4 & 16,2 & 17,4 \\
\hline
\end{tabular}

Valores com mesma letra dentro de cada variedade não diferem entre si pelo teste de Scott Knott à $10 \%$. Para indicação de significância estatística, foram usados $^{\text {ns }}$ (não-significativo); *,**e $* * *($ significativo ao nível de $10 \% ; 5 \%$ e $1 \%$, respectivamente) 
Tabela 2 - Médias de produção de massa seca total $\left(\mathrm{Mg} \mathrm{ha}^{-1}\right)$ separadas em ponteiro e colmo. Teor (\%) e acúmulo de $\mathrm{N}\left(\mathrm{kg}_{\mathrm{g}} \mathrm{h}^{-1}\right)$ no ponteiro de seis variedades de cana-de-açúcar, inoculadas com diferentes estirpes de bactérias diazotróficas

\begin{tabular}{|c|c|c|c|c|c|c|}
\hline \multirow{2}{*}{ Variedades } & \multicolumn{5}{|c|}{ Acúmulo de Matéria Seca Total $\left(\mathrm{Mg} \mathrm{ha}^{-1}\right)$} & \multirow{2}{*}{$\frac{\mathrm{N} \text { total }}{\text { Acúmulo }}$} \\
\hline & Tratamentos & Ponteiro & Colmo & Total & Teor $\mathrm{N}$ & \\
\hline \multirow{6}{*}{ RB867515 } & Controle & $3,2 \mathrm{a}$ & $6,9 \mathrm{~b}$ & $10,1 \mathrm{~b}$ & $1,18 \mathrm{a}$ & $3,78 \mathrm{a}$ \\
\hline & Nitrogênio & $3,3 \mathrm{a}$ & $7,7 \mathrm{~b}$ & $11,1 \mathrm{~b}$ & $1,31 \mathrm{a}$ & $4,32 \mathrm{a}$ \\
\hline & Coquetel & $4,1 \mathrm{a}$ & 9,9 a & $14,0 \mathrm{a}$ & $1,26 \mathrm{a}$ & $5,16 \mathrm{a}$ \\
\hline & BR11512 & $3,2 \mathrm{a}$ & $6,3 \mathrm{~b}$ & $9,3 \mathrm{~b}$ & $1,19 \mathrm{a}$ & $3,80 \mathrm{a}$ \\
\hline & BR 11724 & $4,0 \mathrm{a}$ & $7,8 \mathrm{~b}$ & $11,9 \mathrm{a}$ & $0,96 \mathrm{a}$ & $3,84 \mathrm{a}$ \\
\hline & BR 11411 & $3,6 \mathrm{a}$ & $5,8 \mathrm{~b}$ & $9,4 \mathrm{~b}$ & $0,94 \mathrm{a}$ & $3,38 \mathrm{a}$ \\
\hline \multirow{6}{*}{ RB72454 } & Controle & $2,3 \mathrm{~b}$ & $2,9 \mathrm{a}$ & $5,2 \mathrm{~b}$ & $0,94 \mathrm{~b}$ & $2,16 \mathrm{a}$ \\
\hline & Nitrogênio & $3,6 \mathrm{a}$ & $5,2 \mathrm{a}$ & $8,8 \mathrm{a}$ & $1,11 \mathrm{a}$ & $3,99 \mathrm{a}$ \\
\hline & Coquetel & $1,9 \mathrm{~b}$ & $4,2 \mathrm{a}$ & $6,1 \mathrm{~b}$ & $1,29 \mathrm{a}$ & $2,45 \mathrm{a}$ \\
\hline & BR11512 & $2,5 \mathrm{~b}$ & $4,4 \mathrm{a}$ & $6,9 \mathrm{~b}$ & $0,83 \mathrm{~b}$ & $2,07 \mathrm{a}$ \\
\hline & BR 11724 & $2,6 \mathrm{~b}$ & $4,6 \mathrm{a}$ & $7,2 \mathrm{~b}$ & $0,87 \mathrm{~b}$ & $2,26 \mathrm{a}$ \\
\hline & BR 11411 & $3,5 \mathrm{a}$ & $5,7 \mathrm{a}$ & $9,1 \mathrm{a}$ & $1,13 \mathrm{a}$ & $3,95 \mathrm{a}$ \\
\hline \multirow{6}{*}{ RB92579 } & Controle & $3,7 \mathrm{a}$ & $6,9 \mathrm{a}$ & $9,7 \mathrm{~b}$ & $1,09 \mathrm{a}$ & $4,03 \mathrm{a}$ \\
\hline & Nitrogênio & $4,1 \mathrm{a}$ & $7,1 \mathrm{a}$ & $11,2 \mathrm{a}$ & $1,10 \mathrm{a}$ & $4,51 \mathrm{a}$ \\
\hline & Coquetel & $3,9 \mathrm{a}$ & $5,5 \mathrm{~b}$ & $8,9 \mathrm{~b}$ & $1,20 \mathrm{a}$ & $4,68 \mathrm{a}$ \\
\hline & BR11512 & $3,3 \mathrm{a}$ & $4,4 \mathrm{~b}$ & $7,8 \mathrm{~b}$ & $1,05 \mathrm{a}$ & $3,46 \mathrm{a}$ \\
\hline & BR 11724 & $3,7 \mathrm{a}$ & $9,1 \mathrm{a}$ & $12,7 \mathrm{a}$ & $1,07 \mathrm{a}$ & $3,95 \mathrm{a}$ \\
\hline & BR 11411 & $3,5 \mathrm{a}$ & $6,2 \mathrm{~b}$ & $9,7 \mathrm{~b}$ & $1,01 \mathrm{a}$ & $3,53 \mathrm{a}$ \\
\hline \multirow{6}{*}{ RB918639 } & Controle & $3,4 \mathrm{a}$ & $5,0 \mathrm{a}$ & $8,4 \mathrm{a}$ & $1,18 \mathrm{a}$ & $4,01 \mathrm{a}$ \\
\hline & Nitrogênio & $2,9 \mathrm{a}$ & $3,9 \mathrm{a}$ & $6,9 \mathrm{a}$ & $1,26 \mathrm{a}$ & $3,65 \mathrm{a}$ \\
\hline & Coquetel & $2,5 \mathrm{a}$ & $4,5 \mathrm{a}$ & $7,0 \mathrm{a}$ & $1,42 \mathrm{a}$ & $3,55 \mathrm{a}$ \\
\hline & BR11512 & $3,3 \mathrm{a}$ & $5,3 \mathrm{a}$ & 8,6 a & $1,53 \mathrm{a}$ & $5,04 \mathrm{a}$ \\
\hline & BR 11724 & $4,3 \mathrm{a}$ & $5,3 \mathrm{a}$ & 9,6 a & $1,22 \mathrm{a}$ & $5,24 \mathrm{a}$ \\
\hline & BR 11411 & $3,4 \mathrm{a}$ & $5,1 \mathrm{a}$ & $8,4 \mathrm{a}$ & $1,22 \mathrm{a}$ & $4,14 \mathrm{a}$ \\
\hline \multirow{6}{*}{ RB92606 } & Controle & $2,8 \mathrm{a}$ & $4,0 \mathrm{a}$ & $6,8 \mathrm{a}$ & $1,30 \mathrm{a}$ & $3,64 \mathrm{a}$ \\
\hline & Nitrogênio & $2,5 \mathrm{a}$ & $4,5 \mathrm{a}$ & $7,1 \mathrm{a}$ & $1,05 \mathrm{~b}$ & $2,62 \mathrm{a}$ \\
\hline & Coquetel & $3,4 \mathrm{a}$ & $5,3 \mathrm{a}$ & $8,7 \mathrm{a}$ & $1,00 \mathrm{~b}$ & $3,40 \mathrm{a}$ \\
\hline & BR11512 & $2,6 \mathrm{a}$ & $4,5 \mathrm{a}$ & $7,0 \mathrm{a}$ & $1,35 \mathrm{a}$ & $3,51 \mathrm{a}$ \\
\hline & BR 11724 & $2,8 \mathrm{a}$ & $5,4 \mathrm{a}$ & $8,1 \mathrm{a}$ & $1,48 \mathrm{a}$ & $4,15 \mathrm{a}$ \\
\hline & BR 11411 & $3,2 \mathrm{a}$ & $5,3 \mathrm{a}$ & $8,4 \mathrm{a}$ & $1,36 \mathrm{a}$ & $4,35 \mathrm{a}$ \\
\hline \multirow{6}{*}{ RB855536 } & Controle & $2,7 \mathrm{a}$ & $4,1 \mathrm{a}$ & $6,8 \mathrm{a}$ & $1,29 \mathrm{a}$ & $3,48 \mathrm{a}$ \\
\hline & Nitrogênio & $2,3 \mathrm{a}$ & $4,1 \mathrm{a}$ & $6,7 \mathrm{a}$ & $1,15 \mathrm{a}$ & $2,64 \mathrm{a}$ \\
\hline & Coquetel & $3,1 \mathrm{a}$ & $3,4 \mathrm{a}$ & $6,5 \mathrm{a}$ & $1,04 \mathrm{a}$ & $3,22 \mathrm{a}$ \\
\hline & BR11512 & $3,1 \mathrm{a}$ & $4,2 \mathrm{a}$ & $7,3 \mathrm{a}$ & $1,34 \mathrm{a}$ & $4,15 \mathrm{a}$ \\
\hline & BR 11724 & $2,0 \mathrm{a}$ & $2,8 \mathrm{a}$ & $4,8 \mathrm{a}$ & $1,17 \mathrm{a}$ & $2,34 \mathrm{a}$ \\
\hline & BR 11411 & $2,4 \mathrm{a}$ & $3,2 \mathrm{a}$ & $5,6 \mathrm{a}$ & $1,29 \mathrm{a}$ & $3,09 \mathrm{a}$ \\
\hline \multirow{2}{*}{ F calculado } & Variedade & $5,18 * * *$ & $11,13 * * *$ & $9,50 * * *$ & $1,53^{\mathrm{ns}}$ & $4,19 * *$ \\
\hline & Tratamento & $0,431^{\mathrm{ns}}$ & $1,08^{\mathrm{ns}}$ & $1,25^{\mathrm{ns}}$ & $0,34^{\mathrm{ns}}$ & $0,39^{\mathrm{ns}}$ \\
\hline Tratamento $\mathrm{x}$ Variedade & & $1,469 *$ & $1,52^{*}$ & $1,74^{*}$ & $1,35^{\mathrm{ns}}$ & $1,12^{\mathrm{ns}}$ \\
\hline CV\% Variedades & & 35,9 & 37,7 & 21,5 & 23,0 & 29,3 \\
\hline CV\% Tratamentos & & 25,0 & 27,6 & 21,6 & 20,5 & 28,3 \\
\hline
\end{tabular}

Valores com mesma letra dentro de cada variedade não diferem entre si pelo teste de Scott Knott a 10\%. Para indicação de significância estatística, foram usados ${ }^{\text {ns }}$ (não-significativo); *, **e ***(significativo ao nível de $10 \% ; 5 \%$ e 1\%, respectivamente) 
Não foi observada uma relação direta entre o acúmulo de nitrogênio e o acúmulo de massa seca na variedade RB867515, mas outros efeitos promotores de crescimento podem influenciar diretamente o acúmulo de biomassa (MUTHUKUMARASAMY et al., 2006). Conforme relatado por estes autores, a inoculação combinada com Gluconacetobacter diazotrophicus e Herbaspirillum sp. promoveu o aumento da biomassa da cana-de-açúcar na variedade Co86032 por um período de 45 dias após a inoculação em solo de textura média, aumentando significativamente o acúmulo da parte aérea. Oliveira et al. (2002) observaram incremento significativo de produção de matéria seca aos 200 dias após o plantio de cana ao inocular uma mistura contendo duas estirpes de $G$. diazotrophicus e Azospirillum sp.

A especificidade e a resposta à inoculação por estirpes de bactérias diazotróficas em genótipos de cana-deaçúcar foi demonstrada por alguns autores. Muñoz-Rojas e Caballero-Mellado (2003), em estudo de inoculação no México observaram resposta à inoculação pela estirpe $\mathrm{Pal}^{\mathrm{T}}$ de Gluconacetobacter diazotrophicus na variedade MEX 57-473. Neste estudo também foi observado forte interação entre estirpe bacteriana e variedade de cana.

$\mathrm{Na}$ Índia, Suman et al. (2005) estudou o efeito da inoculação de seis estirpes de G. diazotrophicus associadas a três doses de nitrogênio na variedade CoSe92423, observaram significativo acúmulo de massa seca total nos tratamentos inoculados com as estirpes IS100, IS113 e IS120 na maior dose de nitrogênio, concluindo que além da interação planta-bactéria, a dose do nitrogênio aplicada afeta a resposta a inoculação. Também na Índia, estudos de inoculação foram desenvolvidos por Govindarajan et al. (2006), onde a inoculação de Burkholderia vietnamiensis estirpe MG43 promoveu ganhos de produtividade de 20 e $19 \%$ nas variedades Co 86032 e Co 86027, respectivamente, sendo esta estirpe mais eficiente que outras inoculadas.

Mesmo sendo observadas variações entre respostas e as interações bactérias e genótipos de canade-açúcar, diversos grupos de bactérias têm demonstrado contribuição significativa quando inoculados, seja pela capacidade de fixar $\mathrm{N}$ ou por outros benefícios como promoção do crescimento. Novos estudos devem ser direcionados para a obtenção de respostas à inoculação nas principais variedades cultivadas no Brasil. Dessa forma, a resposta a inoculação em diferentes genótipos com único inoculante seria variada. Buscar um inoculante para cada genótipo de cana-de-açúcar seria inviável operacionalmente. Porém, como demonstrado neste estudo, a inoculação e obtenção de ganhos de produtividade em variedades que ocupam considerável área plantada nos canaviais, como a RB867515, poderá refletir em ganhos econômicos e ambientais.

\section{CONCLUSÕES}

1.A inoculação promove ganhos de biomassa, sendo a contribuição diferente entre variedades e estirpes inoculadas, sugerindo uma interação entre estes fatores;

2.A variedade RB867515 responde positivamente a inoculação do coquetel de bactérias diazotróficas.

\section{AGRADECIMENTOS}

Os autores agradecem ao CNPq e a FAPERJ pelo suporte financeiro e ao CNPq pela bolsa de Mestrado do primeiro autor.

\section{REFERÊNCIAS}

ALVES, B. J. R. et al. Métodos de determinação do nitrogênio em solo e planta. In: HUNGRIA, M.; ARAUJO, R. S. Manual de métodos empregados em estudo de microbiologia agrícola. Brasília: Embrapa-SPI, 1994. cap. 23, p. 449-469. (EmbrapaCNPAF. Documentos, 46).

BALDANI, J. I. et al. A brief story of nitrogen fixation in sugarcane - reasons for success in Brazil. Functional Plant Biology, v. 29, n. 4, p. 417-423, 2002.

BODDEY, R. M. et al. Endophytic nitrogen fixation in sugar cane: present knowledge and future applications. Plant and Soil, v. 252, n. 1, p. 139-149, 2003.

BRASIL. MINISTÉRIO DE MINAS E ENERGIA - MME. Boletim mensal de energia, fevereiro de 2011,2 p. Disponível em: <http://www.mme.gov.br/mme/galerias/arquivos/ publicacoes/ boletins_de_energia/boletins_atuais/01_-_Boletim_Mensal_de_ Energia_-_Fevereiro_2011.pdf>. Acesso em: 8 maio 2011.

BURDMAN, S. et al. Aggregation in Azospirillum brasilense: effects of chemical and physical factors and involvement of extracellular components. Microbiology, v. 144, n. 7, p. 1989-1999, 1998.

CHAPOLA, R. G. et al. Censo varietal de cana-de-açúcar de 2009 dos Estados de São Paulo, Mato Grosso e Mato Grosso do Sul. Sociedade dos Técnicos Açucareiros e Alcooleiros do Brasil, v. 28, n. 4, p. 34-37, 2010.

COMPANHIA NACIONAL DE. ABASTECIMENTO. Acompanhamento de safra brasileira: cana-de-açúcar - safra 2010/2011, terceiro levantamento janeiro/2011. Brasília: CONAB, 2011. 19 p. Dísponível em: <http://www.conab.gov.br/OlalaCMS/ uploads/arquivos/11_01_06_09_14_50_boletim_cana_3o_lev_ safra_2010_2011.pdf>. Acesso em: 09 maio 2011.

DOBBELAERE, S.; VANDERLEYDEN, J.; OKON, Y. Plant growth-promoting effects of diazotrophs in the rhizosphere. Critical Review in Plant Sciences, v. 22, n. 2, p. 107-149, 2003. 
GOVINDARAJAN, M. et al. Improved yield of micropropagated sugarcane following inoculation by endophytic Burkholderia vietnamiensis. Plant and Soil, v. 280, n. 1/2, p. 239-252, 2006.

MUNÕZ-ROJAS, J.; CABALLERO-MELLADO, J. Population dynamics of Gluconacetobacter diazotrophicus in sugarcane cultivars and its effect on plant growth. Microbiology Ecology, v. 46, n. 4, p. 454-464, 2003.

MUTHUKUMARASAMY, R.; REVATHI, G.; VADIVELU, M. Antagonistic potential of $\mathrm{N}_{2}$-fixing Acetobacter diazotrophicus against Colletotricum falcatum went., a causal organism of red-rot of sugarcane. Current Science, v. 78, n. 9, p. 193-198, 2000.

MUTHUKUMARASAMY, R. et al. $\mathrm{N}$ fertilizer saving by inoculation of Gluconacetobacter diazotrophicus and Herbaspirillum sp. in micropropagated sugarcane plants. Microbiological Research, v. 161, n. 3, p. 238-245, 2006.

NEILANDS, J. B.; LEONG, S. A. Siderophores in relation to plant growth and disease. Annual Reviews in Plant Physiology, v. 37, n. 1, p. 187-208, 1986.

OLIVARES, F. L. et al. Occurrence of the endophytic diazotrophs Herbaspirillum spp. in roots, stems, and leaves, predominantly of Gramineae. Biology and Fertility of Soils, v. 21, n. 3, p. 197-200, 1996.

OLIVEIRA, A. L. M. et al. The effect of inoculanting endophytic $\mathrm{N}_{2}$-fixing bacteria on micropropagated sugarcane plants. Plant and Soil, v. 242, n. 2, p. 205-215, 2002.

OLIVEIRA, A. L. M. et al. Yield of micropropagated sugarcane varieties in different soil types following inoculation with diazotrophic bacteria. Plant and Soil, v. 284, n. 1/2, p. 23-32, 2006.

OLIVEIRA, A. L. M. et al. Colonization of sugarcane plantlets by mixed inoculations with diazotrophic bacteria. European Journal of Soil Biology, v. 45, n. 1, p. 106-113, 2009.

PERSELLO-CARTINEAUX, F.; NUSSAUME, L.; ROBAGLIA, C. Tales from the underground: molecular plant rhizobacteria interactions. Plant Cell and Environment, v. 26, n. 2, p. 189-199, 2003.

REINOLD-HUREK, B.; HUREK, T. Life in grasse: diazotrophic endophytes. Trends in Microbiology, v. 6, n. 4, p. 139-144, 1998.
REIS, V. M.; OLIVARES, F. L.; DÖBEREINER, J. Improved methodology for isolation of Acetobacter diazotrophicus and confirmation of its endophitic habitat. World Journal of Microbiology \& Biotechnology, v. 10, n. 4, p. 401-405, 1994.

REIS, V. M. et al. Burkholderia tropica sp. nov., a novel nitrogen-fixing, plant-associated bacterium. International Journal of Systematic and Evolutionary Microbiology, v. 54, n. 6, p. 2155-2162, 2004.

REIS, V. M. et al. Fixação biológica de nitrogênio simbiótica e associativa. In: FERNANDES, M. S. Nutrição mineral de plantas. Viçosa: Sociedade Brasileira de Ciência do Solo, 2006. cap. 6, p. 153-174

REIS, V. M. et al. Eficiência agronômica do inoculante de cana-de-açúcar aplicado em três ensaios conduzidos no Estado do Rio de Janeiro durante o primeiro ano de cultivo. Seropédica: Embrapa Agrobiologia, 2009. 22 p. (Embrapa Agrobiologia. Boletim de pesquisa e desenvolvimento, 45).

RODRIGUEZ, H.; FRAGA, R. Phosphate solubilizing bacteria and their role in plant growth promotion. Biotechnology Advances, v. 17, n. 4/5, p. 319-339, 1999.

SEVILLA, M. et al. Contributions of the bacterial endophyte Acetobacter diazotrophicus to sugarcane nutrition: A preliminary study. Symbiosis, v. 25, n. 1/3, p. 181-191, 1998.

SILVA, M. F. et al. Inoculantes formulados com polímeros e bactérias endofíticas para a cultura da cana-de-açúcar. Pesquisa Agropecuária Brasileira, v. 44, n. 11, p. 1437-1443, 2009.

SOCCOL, C. R. et al. Bioethanol from lignocelluloses: Status and perspectives in Brazil. Bioresourse Technology, v. 101, n. 13 , p. $4820-4825,2010$.

De SOUZA, E. L. L; MACEDO, I. Etanol e bioeletricidade: a cana-de-açúcar no futuro da matriz energética. UNICA União da Indústria de Cana-de-açúcar São Paulo: 2010, 314 p.

SUMAN, A. et al. Improving sugarcane growth and nutrient uptake by inoculating Gluconacetobacter diazotrophicus. Plant Growth Regulation, v. 47, n. 2/3, p. 155-162, 2005.

URQUIAGA, S.; CRUZ, K. H. S.; BODDEY, R. M. Contribution of nitrogen fixation to sugar cane nitrogen15 and nitrogen balance estimates. Soil Science Society American Journal, v. 56, n. 1, p. 105-114, 1992. 